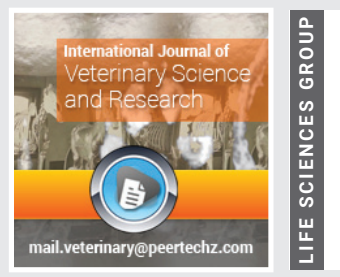

\title{
Systematic review and meta- analysis of animal listeriosis in Ethiopia
}

\author{
Sagni Diba* and Habtamu Terefe
}

Ministry of Agriculture, Addis Ababa, Ethiopia

Check for updates

Received: 10 March, 2021

Accepted: 05 April, 2021

Published: 06 April, 2021

*Corresponding author: Segni Diba, Ministry of Agriculture, Addis Ababa, Ethiopia,

Email: segni.diba2007@gmail.com

Keywords: Animals; Ethiopia; Food contamination; Listeriosis; Meta-analysis

https://www. peertechzpublications.com

\begin{abstract}
Listeriosis is a widespread zoonotic disease that becomes an important source of food borne infections all over the world. Mostly it affects cattle herd, sheep and goat flocks. The objective of the research was to estimate prevalence of Listeriosis in Ethiopia and to provide the distribution of the disease at national level. The metaanalysis was conducted to collect the information and to provide a pooled prevalence estimate at national level and identify potential predictors. The secondary data were searched from Published research and review written by English language during the period between October, 2000 and June 2018 . The publications were selected based on inclusive and exclusion criteria for data extraction and analysis by Meta-Analysis Software Relevant animal level data on 1460 was collected from 14 published manuscripts and one master's thesis resulting conformed to predefined criteria. The dataset was analyzed using a meta-analytical technique. The pooled prevalence assessed computed for listeriosis problem was $23.9 \%$ with confidence interval of $17.6,30.2$. Among the predictors considered for heterogeneity analysis only sample size and listeriosis the prevalence was showed to decrease with increasing sample size. This study showed occurrence of animal listeriosis at national level.
\end{abstract}

Thus, approach used to know the prevalence of the disease at national level.

\section{Introduction}

Listeriosis is unimportant emerging food borne of bacterial zoonotic infections in worldwide [1]. It is occurred in 1920 for the first time as an infectious disease of rodents and small animals [2]. From listeria species L. monocytogenes primarily affects older, adults, pregnant women, and newborns with weakened immune systems [3]. Because ingested with poorly preserved silage and contamination of food in animal (unfermented feed) and human, absences of acidity enough to kill the bacteria [4].

Epidemiological distribution of Listeriosis changing now a day, the pathogen has been occurred some has spread in Ethiopia. In different part of country the study were reported in different area with different prevalence $[5,6]$. The areas in which the disease is distributed are specially established at central the part of the country [7]. From those towns Bishoftu and Selale are well known because growth in the dairy industry $[8]$.

Animal products and poultry were sources of infection. From listeria species L. monocytogenes in human well known on the status of food borne listeriosis [3].The general symptom of the disease was fever, watery diarrhea, nausea, headache, and pain in joints and muscles [9]. The diagnosis methods of disease are Oxford agar, isolation of agents, FA, inoculation, serological technique, and Molecular methods [10]. Combination of antibiotics used for treatment of the disease [11]. Good hygienic practice and proper bio-security was the control methods of disease [12].

The listeriosis is bacterial zoonotic in both veterinary and human's pathogen. In Veterinary the bacteria causes basilar meningitis and still birth, Although in human pathogen causes infection especially immune suppressed, elder, pregnant human population [13]. Economically the disease importance to loss of production due to abortion, treatment cost, reduces trade of animal $[14,15]$. In Ethiopia Contamination of animal products considered as a sources of disease. There does not know the pooled prevalence to assess the distribution of Listeria species in the country level. Therefore, the quantitative synthesis of research assessed important to know level of disease distribution. The objective of the study was to estimate prevalence of disease in by meta-analysis software and to provide good distribution of the disease at national level. 


\section{Materials and methods}

\section{Study protocol}

Study standard was collecting secondary data and categorized inclusion and exclusion criteria. Two types of guidelines and a data extraction method were developed. The primarily was a standard for preliminary screening depends on title of research and abstract contents. The second standard included specific criteria to assist in categorized valid studies that were in line with the objective of the study. The approach ensured compliance with PRISMA guideline for review processes [16].

\section{Literature search}

Electronic secondary data search methods were used. Key words such as "Listeria species", or "L. monocytogenes", "food of animal origin", "antimicrobials susceptibility of listeria species" or "bovine milk" or "Dairy farms operational stages")) " AND Ethiopia are used. Data bases including, PubMed, African Journals Online (AJOL), Web of science and Google scholar was used. The reference lists of published manuscripts First screening and specific screenings were done. Those studies fulfill the criteria were included in analysis. The duration of literature search was 01, November 2019 to 30, June 2020.

\section{Inclusion and exclusion criteria}

The criteria for identifying Ethiopian authors were Manuscripts written only in English and published Studies were assessed primarily based on their objective, design, data analysis and presentation. The specific inclusion criteria include were Publication year after 01 January 2000 to 30 November 2019. Cross sectional study design. Random sampling (systematic random) of the study population, Clarity of result presentation and the diagnostic methods used to identify infected subjects. The inclusion criteria were used for be eligible: Published in a reputable journal, Written in English, Cross-sectional study design and Published after 01 January 2000 to 30 march 2019.

\section{Data extraction and quality assessment}

The standard for collection methods depends; name of the author, year of publication, species affected, region, sample size, number positives, number negatives, prevalence and respective $95 \%$ CI. Extracted data were written on Excel sheet.

\section{Meta analysis}

Descriptive statistics were applied to determine the total number species included at each level of analysis [17]. Randomeffects model was used to pool the estimations. Outcomes were the total prevalence of listeriosis in Ethiopia. Results of the meta-analysis were shown as a forest plot diagram. Q-test and $\mathrm{I}^{2}$ statistics were used to examine heterogeneity of studies. Subgroup metaanalysis was utilized to estimate the pooled prevalence of CE in small ruminants by stratifying the species. STATA-11 software and meta-prop one described on were used to analysis.

\section{Publication bias assessment}

Funnel plots were used to obtain visual impressions acrossstudy bias. Begg's and Egger's tests were used to assess the statistical significance of the bias noted [18].

\section{Result}

\section{Literature search results}

Literature search results by using the secondary data from internet and manual search resulted in 48 published researches and master's research. 29 of them were totally failed due to criteria.

During inspection of the individual thesis, 5 of them had lack of methodology; others are due to sampling methods and study design that forced us to question the internal validity of the estimates for the study population. Finally 13 published articles and one master's thesis met used based on the criteria; Ethiopian authors, written only in English language, their objective, study design, sampling methods, year of publication, data analysis and presentation were the minimum acceptable standard to be included in this review (Figure 1).

\section{Meta-analysis}

The pooled prevalence estimate of listeria infection was $23.9 \%$ with $95 \%$ CI: $17.6,30.2$. In a random effect model, the calculated Cochran value $(Q)$ was $387.39(\mathrm{df}=12$ and $\mathrm{p}=0.000)$. The raw and logit-transformed effect size distribution is given on. The effect size and respective weight of each eligible study report in the review is also presented the forest plot (Figure 2). The variation among studies was significant attributable to heterogeneity between studies. The magnitude of this true variation is high $\left(\mathrm{I}^{2}=96.9 \%\right)$.

\section{Publication bias assessment}

In the publication bias analysis based on the Begg's and Egger's statistics were seen to have $p$ value $=0.000$. The parameters were consistent with what is observed on the funnel plot (Figure 3) and suggests the presence of bias to the right side that could be linked to more study reports with higher prevalence estimate.

\section{Discussion}

Direct transmission listeria species from infected animals or from contaminated animal products [19]. Listeria species was to any environments conditions. The Meta analysis result, the overall prevalence of liisteriosis was $23.9 \%$. The variation is due to origin of isolation, seasonal variability and geographical distribution (Favaro, et al. 2014). The result of studies included serotype $4 \mathrm{~b}, 1 / 2 \mathrm{a}$, and $1 / 2 \mathrm{~b}$ as the most prevalent serotype. However serotype can be variable during different samples type. According to wang, et al. 2013 report in shangi china the majority of the isolates belonged to serotypes $1 / 2 \mathrm{a}$ and $1 / 2 \mathrm{~b}$. The studies reported from turkey the presence of four different serotype $(1 / 2 \mathrm{a}, 1 / 2 \mathrm{~b}, 1 / 2 \mathrm{c}$ and $1 / 4 \mathrm{~b})$ in isolates obtained from milk and dairy products [20]. 


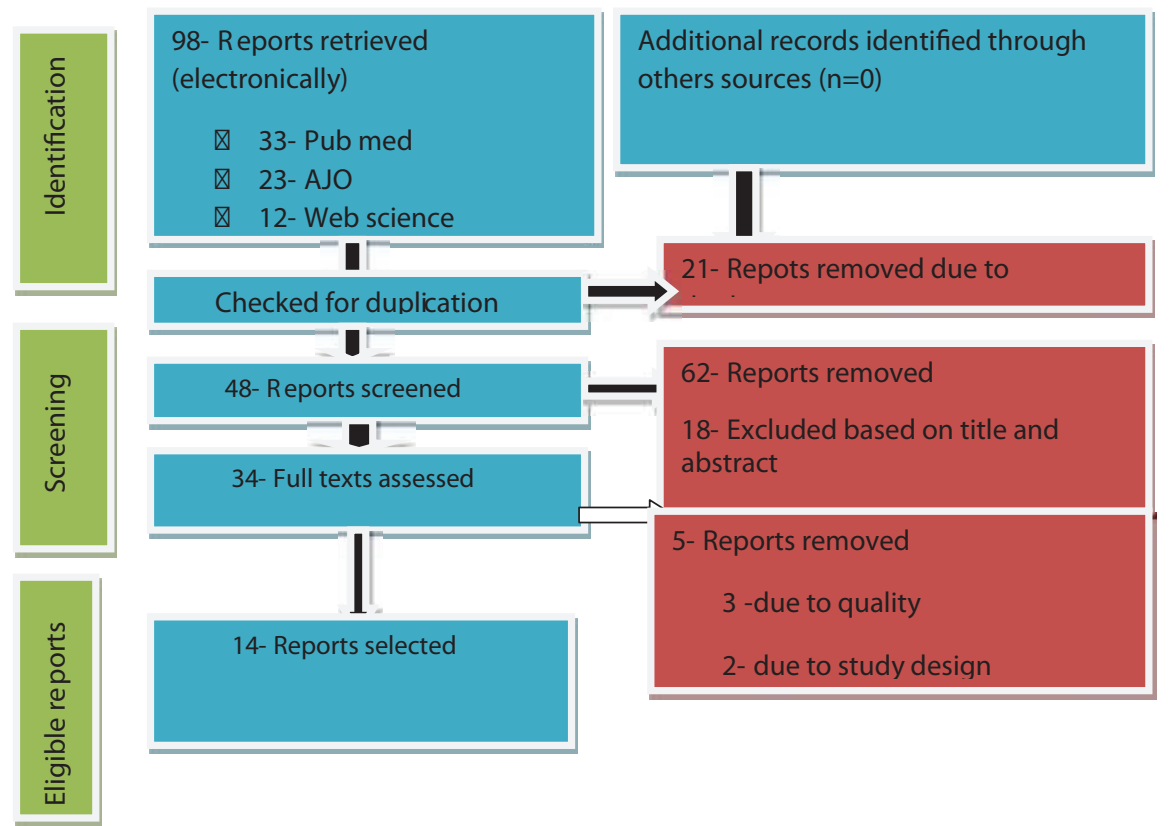

Figure 1: Flow diagram for Meta analysis process.

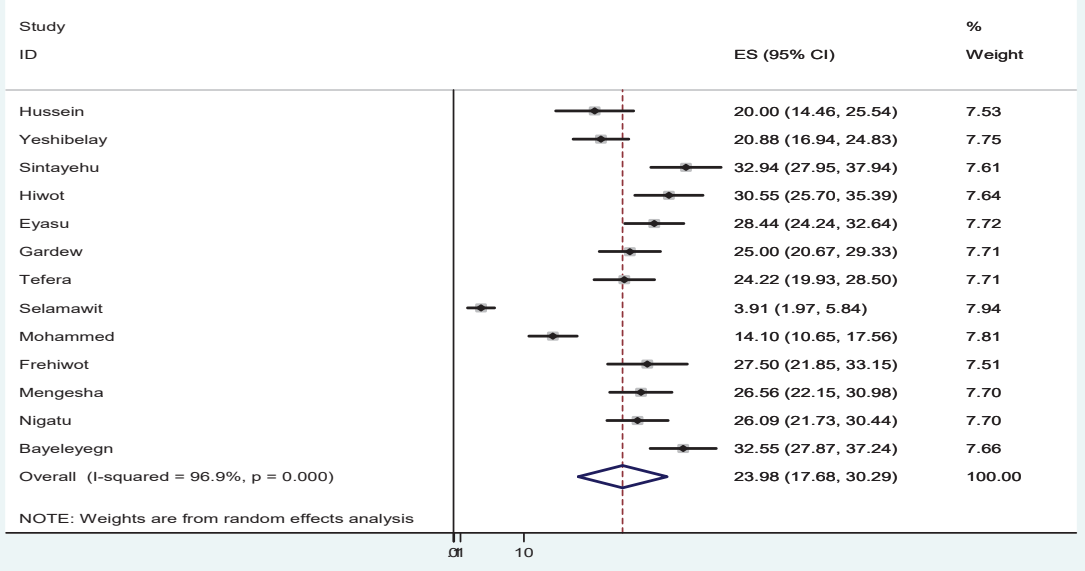

Figure 2: Forest plot on listeria infection logit-prevalece estimate in Ethiopia.

In Ethiopia, prevalence of the listeosis is well established. Hence the real causes of these differences in the prevalence of the listeria species are clear for all the population of animals. The prevalence of listeriosis is common in the farm level as study reported by Garedew et al., 2015 in Gonder. Listeria prevalence was high in meat and milk. However, the study shows all prevalence from the animal products not live [11]. Infection may result in an obvious clinical disease, such that the affected animals may not be marketable [13].

listeria transmission due to direct contact between animals and human due to poor hygiene. Investigators reported listeria monocytegen is more common in the area of country than other listeria species. Besides, more of farm sourced of the disease than other animals relatively.

There are Limitations in our analysis first; due to lack of study on listeria species in many regions of the country. Secondly the finding not fully indicates the prevalence of the disease in country because the prevalence of listeria species has not yet been surveyed in many studies conducted in Ethiopia. Third heterogeneity was detected among the included studies therefore the results should be interpreted with caution.

\section{Conclusion and recommendation}

The study to show the distribution of the disease in country level and to shows the status of the disease especially epidemiological evidence. The disease affected humans due to sources of contamination for susceptible groups. In addition, as explained above L. monocytogenes is proved to be sensitive to many and available drugs. So, appropriate drug selection for Listeriosis and checking for effectiveness must be made as routine way in food microbiology laboratories. 


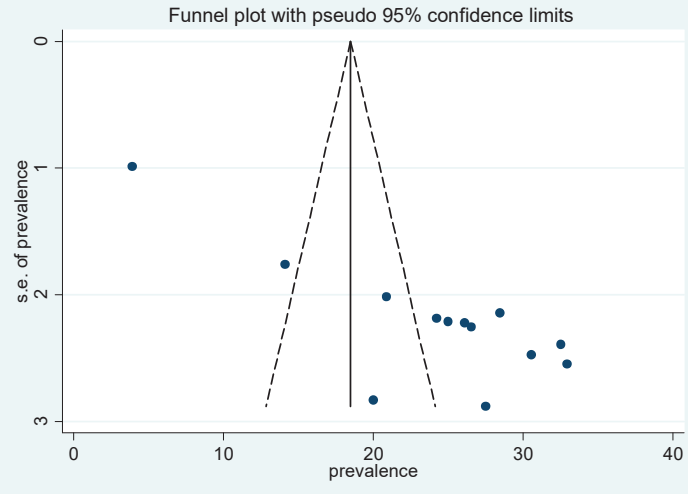

Figure 3: Funnel plot for logit-prevalence estimate of listeria infection studies Ethiopia.

\section{Based above information the following recommenda- tions are forwarded}

$>$ Proper silage preparation and maintaining good storage conditions.

$>$ A further detection of L. monocytogenes and other Listeria species in animal, animal feeds and the dairy farm environments and further contaminating risk.

$>$ Factors assessment in Ethiopia Creating public awareness on the zoonotic risk associated with Listeria along dairy industry needed.

\section{References}

1. Kalorey D, Warke S, Kurkure N, Rawool D, Barbuddhe S (2008) Listeria species in bovine raw milk: A large survey of central India. J Food Control 19: 109-112. Link: https://bit.ly/3sQEdx9

2. Painter J, Slutsker L (2007) Listeriosis in human listeriosis and Food Safety. $3^{\text {Ed }}$. Eds, Ryser, Tand, Marth. CRC Press, Taylor and Francis Group Boca Raton, Florida, USA 85110. Link: https://bit.ly/2PX7Bmu

3. Molla B, Yilma R, Alemayehu D (2004) Listeria monocytogenes and other Listeria species in retail meat and milk products in Addis Ababa, Ethiopia. $J$ Health Development 18: 131-212. Link: https://bit.ly/3umAAPQ

4. Garedew L, Taddese A, Biru T, Nigatu S, Kebede E (2015) Prevalence and antimicrobial susceptibility profile of listeria species from ready-to-eat foods of animal origin in Gondar Town, Ethiopia. BMC Microbiol 15: 100. Link: https://bit.ly/3sPxZO0

5. Tsehay R (2002) Small-scale milk marketing and processing in Ethiopia In: Rangnekar D, Thorpe W, eds. Smallholder dairy production and marketing opportunities and constraints. Nairobi, Kenya: International Livestock Research Institute (ILRI). Link: https://bit.ly/3sRrcTW
6. Central Statistics Agency (CSA) (2001) Report on the 1999/2000 household and expenditure survey. Addis Ababa, Ethiopia.

7. Yilma Z (2010) Quality factors that affect Ethiopian formal milk business experience from selected dairy potential areas. Addis Ababa, Ethiopia. Netherlands Development Organization (SNV). Link: https://bit.ly/3wrvNhQ

8. Tegegne A, Gebremedihin B, Hoekstra D (2007) Rural urban linkage in marketoriented dairy development in Ethiopia; lesson from the Ada's co-operative. Addis Ababa. Link: https://bit.ly/3umKxwt

9. Ooi L, Lorber B (2005) Gastroenteritis due to Listeria monocytogenes. Clinica Infectious Diseases 40: 1327-1332. Link: https://bit.ly/3wpOQsN

10. Hitchins A (2002) Detection and enumeration of Listeria monocytogenes in foods. In: Bacteriological Analytical Manual online. $8^{\text {th }}$ ed.

11. Radostits O, Gay C, Hincheliff K, Constable P (2007) Diseases associated with Listeria species: Veterinary Medicine, a Textbook of the disease of Cattle, Sheep, Pigs, Goats and Horses. 10 Ed. Saunders Elsevier Published Ltd, London 805-810.

12. Andrew A, Blowey R, Boyd H, Eddy R (2004) Bovine Medicine Diseases and Husbandry of cattle. 2 ed. Blackwell Science Ltd a Blackwell Publishing Company 1232

13. Aureli P, Fiorucci GC, Caroli D, Marchiaro G, Novara O, et al. (2001) An outbreak of febrile gastroenteritis associatedwith corn contaminated by Listeria monocytogenes. N EnglJ Med 342: 1236-2000. Link: https://bit.ly/3wvIMjx

14. Pal M, Awel H (2013) Public Health Significance of Listeria monocytogenes in Milk and Milk Products: An Overview, Department of Microbiology, Immunology and Public Health, College of Veterinary Medicine and Agriculture, Addis Ababa University, P.O. Box No, 34, Debre Zeit, Ethiopia.

15. Tewodros F, Atsedewoyne F (2012) Listeriosis in Small Ruminants: Advance in Biological Research 6: 202-209.

16. Nyaga V, Arbyn M, Aerts M (2014) Metaprop: a Stata command to perform Meta analysis of binomial data. Arch Public Health 72: 39. Link: https://bit.ly/20rFJqw

17. Allerberger $F$, Wagner $M(2010)$ Listeriosis a resurgent food borne infection. Clin microbial infect 16: 16-23. Link: https://bit.ly/3sSARth

18. Zeng X, Zhang Y, Kwong J, Zhang C, Li S, et al. (2015) The methodological quality assessment tools for preclinical and clinical studies, systematic review and meta-analysis, and clinical practice guideline: a systematic review. J Evid Based Med 8: 2-10. Link: https://bit.ly/3cN4TZQ

19. Kevenk T, Terzi G (2016) Prevalence, antimicrobial resistance and serotype distribution of listeria monocytogenes isolated from raw milk and dairy products. J Food Saf 36: 11-18. Link: https://bit.ly/39ZRZpR

20. Tambekar D, Dhanorkar D, Gulhane S, Dudhane M (2007) Prevalence, profile and antibiotic susceptibility pattern of bacterial isolates from blood. J Med Sci 7: 439-442. Link: https://bit.ly/3sRWiea 